\title{
LOS PROBLEMAS DE REDACCIÓN DE LOS ESTUDIANTES COSTARRICENSES: UNA PROPUESTA DE REVISIÓN DESDE LA LINGÜÍSTICA DEL TEXTO
}

\author{
Carlos Sánchez Avendaño
}

\begin{abstract}
RESUMEN
En este artículo se presentan algunos elementos de la lingüística del texto (cohesión, coherencia e informatividad) como una alternativa para analizar los problemas de expresión escrita de los estudiantes universitarios costarricenses y, en última instancia, como una llamada de atención sobre la necesidad de replantear la enseñanza de la redacción.

Palabras clave: lingüística del texto, expresión escrita, enseñanza de la redacción, Costa Rica.
\end{abstract}

\begin{abstract}
In this article some elements from Text Linguistics (cohesion, coherence and informativity) are introduced as an alternative to analyze the problems in college Costa Rican students' written communication and, finally, as a means to draw attention to the necessity of restating the teaching of composition.

Key words: Text Linguistics, written communication, teaching of composition, Costa Rica.
\end{abstract}

"Dios mío, qué mal escribo, nada tiene orden, qué delicia...Conocer el mal es amarlo. Voy a ver si puedo meter alguna cacofonía pronto"

Alí Víquez Jiménez, "Caminos en la selva" (Biografías de hombres ilustres. 2002)

M.L. Carlos Sánchez Avendaño. Profesor de la Escuela de Filología y Lingüística de la Universidad de Costa Rica. Recepción: 21-02-2005

Aceptación: 01-03-2005 


\section{Introducción}

Hace tiempo se viene comentando, con cierto estupor, que los estudiantes universitarios presentan serios problemas de expresión escrita. En la prensa, en medios académicos y profesionales se alzan, reiteradamente, voces de alerta sobre una situación que se considera inadmisible en personas con un alto nivel de instrucción formal, especialmente porque todas ellas ya han pasado por once años de escolarización en la que aprobaron una materia relativa a la enseñanza de la lengua materna ("Español").

Ante este panorama, desde 1985 han visto la luz varios estudios cuya finalidad consistía en diagnosticar cuáles eran los principales problemas de expresión escrita de los estudiantes costarricenses y proponer acciones remediales al respecto. No obstante, creemos que, en alguna medida, el abordaje teórico de la problemática no ha permitido dimensionar con toda claridad cuál es la naturaleza de este, dado que en ocasiones se ha perdido de vista que lo que se encuentra en juego es la calidad de la redacción de los textos en cuanto tales, aspecto a veces oscurecido por la preocupación de corte normativo-purista que se ha asumido.

En nuestro criterio, al considerar las características y deficiencias de la redacción de un individuo, debe partirse de una perspectiva textual; es decir, deben analizarse los escritos en función de su carácter de textos, de manifestaciones discursivas concretas, no a partir de nociones de gramática tradicional ni de lingüística estructural, pues lo que interesa no son las unidades teóricas de análisis (oraciones, cláusulas, frases, morfemas), sino lo que se conoce como textualidad. Es por ello que nos proponemos revisar las deficiencias en las redacciones de los estudiantes universitarios desde una postura teórica que consideramos apropiada para el objeto de estudio: la lingüística del texto, con el fin de mostrar una nueva manera de concebir el problema y, en última instancia, la solución.

\section{Estado de la cuestión}

Básicamente, son tres los estudios que asumen el diagnóstico de los problemas de expresión escrita del estudiantado costarricense de nivel superior (secundaria y universidad).

El estudio que abre el estado de la cuestión se realizó a partir de textos escritos por estudiantes de la Universidad Estatal a Distancia. Se trata del trabajo de Rodino y Ross (1985), en el que los autores proponen la hipótesis de que las deficiencias en la escritura reveladas en sus datos apuntan a una interferencia de patrones propios de la oralidad en el registro escrito; en otras palabras, los sujetos muestran problemas para discernir cuáles elementos pertenecen a un registro o a otro y un escaso control e, incluso, desconocimiento, de los parámetros de construcción de los textos escritos, lo que los lleva a escribir tal y como hablan coloquialmente. Para Rodino y Ross, entonces, los problemas son, muchas veces, de competencia lingüística.

La investigación de Rojas y Umaña (1986), llevada a cabo a partir del análisis de redacciones (prueba no estructurada) y pruebas estructuradas aplicadas a estudiantes de último año de colegio, también se ocupó especialmente del componente gramatical. Según la prueba no estructurada, hubo un desempeño bueno o aceptable en el manejo de la morfosintaxis nominal, sintaxis verbal, formas adverbiales y nexos. Por el contrario, en casi todos esos mismos aspectos, los resultados de la prueba estructurada muestran una calificación por debajo del nivel de aceptabilidad ${ }^{1}$. 
En el nivel léxico (variedad, palabras comodines, formas cultas, préstamos, propiedad en el uso), ninguna de las dos pruebas arrojó resultados favorables. Tampoco los rubros relacionados con la estructuración del mensaje (cacofonía, subordinación recargada, estructura del escrito, secuencia y riqueza de ideas, orden general de la oración) dieron buenos resultados: apenas un 51\% de aprobación. En varias ocasiones, los autores achacan los problemas encontrados a una falta de planificación, que se traduce en la expresión de ideas inconexas.

La conclusión más interesante del estudio de Rojas y Umaña consiste en la determinación de que, aunque en la prueba no estructurada no se encontraron problemas con el manejo del registro escrito, sí se nota una subutilización de los recursos gramaticales del idioma y poca variedad léxica. Asimismo, la puntuación se restringe al uso de unos pocos signos, y los textos son incompletos, no desarrollan un mensaje de forma apropiada, no existe una adecuada conexión entre las ideas, ni planeamiento. Todo ello lleva a los autores a afirmar que la redacción de los alumnos muestra un uso restringido de las posibilidades del idioma.

Esta misma línea de análisis la desarrollará posteriormente Rojas (1987) en su artículo "Análisis del nivel discursivo: Registros escritos de undécimo año". En este, la autora parte del nivel del discurso como aquel conformado por los aspectos más allá de la frase con repercusiones en la eficiencia comunicativa del texto. En general, se trata de los mismos elementos analizados en el corpus de su investigación anterior, pero con un mayor énfasis en el comentario de ciertas características. Entre ellas: pocas redacciones presentan los elementos de introducción, desarrollo y conclusión, con orden lógico-temporal de las ideas y nuevos aspectos del tema tratado. En el nivel conceptual es quizás en el que el artículo de Rojas devela mayor interés: se nota una falta de planificación del contenido, por lo que las ideas no se muestran en una secuencia y el texto resulta redundante, oscuro o vacío. En suma, las redacciones evidencian que sus autores están ceñidos a la inmediatez del contexto.

Por último, de acuerdo con la tesis de Jiménez (1987), realizada con escritos de estudiantes de la Sede de Occidente de la Universidad de Costa Rica, los problemas se pueden resumir en los siguientes aspectos: puntuación descuidada y desconocimiento de sus usos más básicos; exceso de subordinación, provocada por el descuido en la puntuación; pobreza de ideas: poca variedad y mucha repetición; alteración del orden lógico y sintáctico de la estructura oracional; desajuste temático entre el título y el contenido; desconocimiento del uso del párrafo, en su estructura externa y su unidad interna; repetición de palabras, barbarismos, cosismos, alguismos, oseísmos, etceterismos, verbos fáciles, queísmos y falta de sinónimos.

Como se puede apreciar, pese a tratarse de problemas de redacción, aparte de algunos elementos tratados por Rojas (1987), no se han abordado las deficiencias desde una perspectiva discursiva que permita evaluar el problema en su dimensión textual, no en su microcomposición al analizar segmentos aislados; es decir, no se han estudiado los problemas en el empleo de los elementos lingüísticos dentro de la totalidad del texto, sino separados unos de otros, lo que no posibilita darse una idea de la calidad de los textos en cuanto tales. Asimismo, exceptuando la investigación de Rodino y Ross (1985), los diagnósticos realizados adolecen de un tinte claramente purista en el abordaje del problema, enfoque que en muchas ocasiones guarda poca relación con la calidad de la redacción en cuanto texto y que se pierde en nimiedades del tipo "lo correcto es 'de acuerdo con' y no 'de acuerdo a"". 


\section{El corpus estudiado}

El corpus estudiado para este artículo consiste en 60 redacciones de estudiantes de primer ingreso a la Sede Rodrigo Facio de la Universidad de Costa Rica, empadronados en diversas carreras. Estas 60 redacciones, solicitadas específicamente para esta investigación, se escogieron al azar de un grupo de unos 150 textos; 30 son de estudiantes que cursaron la secundaria en un colegio público y las otras 30, de estudiantes graduados de colegios privados. En un principio, se pensó en estudiar el impacto de la variable 'tipo de colegio de procedencia' en la calidad de la redacción, pero el análisis posterior no arrojó ningún resultado a este respecto.

A todos los estudiantes se les pidió que escribieran una redacción de una página y media de extensión sobre algún problema de Costa Rica y sus posibles soluciones, la cual debía concebirse como un texto formal que iba a ser leído por un profesor universitario y que tendría una calificación. De esta forma, se les indicó implícitamente a los alumnos que se trataba de un texto académico, el tipo de escritura que nos interesa en esta investigación.

En general, los textos académicos están vinculados a los textos científicos, cuyos objetivos últimos consisten en informar y convencer. Sin embargo, los escritos académicos están determinados por el contexto académico que justifica su producción y ciertos rasgos particulares según su propósito. Así, un examen tendrá la finalidad de mostrar ante un juez evaluador que se ha comprendido la materia; en un libro de texto, por su parte, debe primar el componente didáctico (Figueras 2000). Podríamos decir que las redacciones solicitadas cumplen el objetivo de informar sobre un problema y disuadir al lector sobre una posición en torno a este (causas, consecuencias, soluciones, etc.), tal como lo haría un ensayo para cualquier curso universitario.

\section{La lingüística del texto y los estándares de textualidad}

A pesar de su utilidad como herramientas para poder explicar el funcionamiento del lenguaje, las oraciones, frases, morfemas y demás unidades de análisis lingüístico no pasan de ser nociones teóricas. En la realidad comunicativa de los hablantes, lo que existe son textos emitidos en situaciones comunicativas concretas y con una finalidad también específica. Este es, básicamente, el principio que subyace a la concepción del estudio del lenguaje de disciplinas tales como el análisis del discurso, la lingüística del texto y la pragmática. En particular, la lingüística textual se ha concentrado en el estudio de los tipos, estructuras y propiedades de los textos.

El concepto de texto, no obstante, no parece ser de fácil definición. Usualmente, lo que se entienda por texto va a depender de la perspectiva teórica de partida. En general, se suele hablar de que un texto se determina por poseer unas características fundamentales, que en conjunto crean la condición de "textura discursiva". Dichas características o elementos lingüísticos se encuentran interrelacionados y organizados, de manera tal que los hablantes son capaces de reconocer una o más emisiones como conformadoras de un mismo texto o como textos distintos. En este sentido, las nociones de completud y cohesión son fundamentales para comprender en qué consiste la unidad semántico-pragmática que denominamos 'texto'.

Desde la perspectiva de la lingüística textual representada por de Beaugrande y Dressler (1997: 35), "un texto es un acontecimimiento comunicativo que cumple siete normas 
de textualidad. Si un texto no satisface alguna de esas normas entonces no puede considerarse que ese texto sea comunicativo. Por consiguiente, los textos que no sean comunicativos no pueden analizarse como si fueran textos genuinos". Precisamente, en muchas de las definiciones lingüísticas contemporáneas del concepto 'texto', se recurre a una caracterización de los requisitos que se deben satisfacer para que algo se pueda considerar como tal; entre estos requisitos, las llamadas normas o estándares de textualidad ocupan una posición prominente, en especial las condiciones de coherencia y cohesión.

En concreto, lo que interesa destacar en el enfoque textual es la concepción de los textos como unidades comunicativas de sentido; es decir, interactivas, intencionales, semánticopragmáticas, en las que sus componentes confluyen para dar la idea de unidad.

El modelo de Dressler y de Beaugrande, declaradamente de naturaleza cognoscitiva, se concentra, entonces, en los principios constitutivos de un texto. Para ellos, estos siete estándares son: la cohesión y la coherencia, relativas al texto propiamente dicho; la intencionalidad y la aceptabilidad, esto es, las facetas centradas en los usuarios; la situacionalidad y la intertextualidad, reveladoras del carácter interactivo de los textos; y la informatividad, representante de la calidad y pertinencia del evento comunicativo. Estos siete parámetros estarían, a su vez, regidos por tres principios reguladores de la comunicación: la eficacia, la efectividad y la adecuación. De todas estas nociones, la cohesión y la coherencia son las que han recibido la mayor atención, como se verá posteriormente en nuestro análisis.

Ciertamente, este modelo de composición textual no fue elaborado con una finalidad ni didáctica ni, mucho menos, normativa. Es decir, no se trata de una propuesta para enseñar a redactar textos de calidad ni para juzgarlos; sin embargo, creemos que se puede adaptar a la perfección para los propósitos que nos competen aquí.

En última instancia, si la instrucción lingüística tiene como objetivo esencial dotar a los educandos de elementos que les permitan perfeccionar su habilidad para crear y comprender textos, orales o escritos, de forma tal que estos sean óptimos para los propósitos comunicativos del emisor y sus interlocutores, creemos que la perspectiva textual es la más apropiada para estudiar las características de las redacciones que nos atañen, como lo haremos a continuación.

\section{La redacción de los estudiantes universitarios desde la lingüística del texto}

A continuación examinaremos el corpus de redacciones en relación con tres de las normas de textualidad tal y como las exponen de Beagrande y Dressler (1997); no obstante, la concepción de los fenómenos y la exposición las hemos enriquecido con diversas fuentes teóricas. Nuestro análisis es de tipo cualitativo, pues resulta sumamente difícil intentar cuantificar aspectos discursivos como los aquí tratados; empero, cuando el elemento lingüístico lo ha permitido, hemos llevado a cabo cierta contabilización en otras monografías relativas al tema (véase Sánchez Avendaño b, c). Nos concentramos, entonces, en tres de los estándares que se pueden evaluar a partir del producto escrito final, a saber: la cohesión, la coherencia y la informatividad. 


\subsection{La cohesión}

La cohesión es quizás el estándar de textualidad de más fácil captación y estudio, por cuanto guarda relación con marcas patentes que coadyuvan a dotar de unidad a un texto. Precisamente, para algunos autores se trata de una especie de coherencia de nivel superficial (Lozano et al. 1999) o una manifestación de esta a partir de rubros verbales materiales (Calsamiglia y Tusón 2002).

La cohesión, entonces, se produce intratextualmente, gracias a una red de enlaces que funcionan en conjunto para establecer la unidad semántica de un texto a partir de las relaciones explícitas entre los elementos que lo componen (párrafos, proposiciones, enunciados, etc.). Desde la perspectiva de Halliday y Hasan (citados por Brown y Yule 1993: 236), "las relaciones de cohesión dentro de un texto se establecen 'cuando la interpretación de algún elemento del discurso depende de la de otro. Aquel presupone éste en el sentido de que no puede ser decodificado sin recurrir a él"'.

Para de Beaugrande y Dressler, los textos son un tipo de sistema y, como tales, hacen depender su estabilidad en la continuidad de los elementos integrativos; esto es, existen unos rubros que permiten acceder a otros rubros dentro de un mismo texto, en vista de que están vinculados. Desde su perspectiva cognoscitiva, la cohesión tiene que ver con mecanismos relativos al almacenamiento de la información y la restringida capacidad de la memoria operativa. En su propuesta, el contenido conceptual se guarda en una memoria de largo plazo, mientras que los materiales lingüísticos superficiales se almacenan en la memoria de trabajo, por definición, cortoplacista. De ahí que la sintaxis cumpla la función de marcar dependencias entre elementos distantes dentro de un mismo texto (por ejemplo, un pronombre y su respectivo sustantivo correferencial), con el fin de que sean más accesibles y fácilmente almacenables. Se trata, a fin de cuentas, de que los rubros ya empleados se puedan reutilizar, comprimir o modificar en el texto mediante determinados recursos verbales y operaciones discursivas: repetición, sustitución, elisión y conexión.

En este artículo nos dedicaremos al examen de dos de los mecanismos cohesivos más importantes: el mantenimiento del referente por procedimientos léxicos y el mantenimiento por procedimientos gramaticales. En otras publicaciones, hemos estudiado ya a profundidad otros dos recursos: los conectores discursivos (Sánchez Avendaño c) y el establecimiento de las unidades textuales por medio de la puntuación (Sánchez Avendaño b). Aunque Brown y Yule (1993: 253) son muy enfáticos en cuanto a que lo que interesa, en el análisis del discurso, son las referencias acertadas y no las correctas ${ }^{2}$, nuestro análisis, por trabajar con los textos como productos sin saber a ciencia cierta cuál sería la actitud del lector, hará caso omiso de esta salvedad.

\subsubsection{La cohesión a través del mantenimiento del referente por procedimientos léxicos}

Un texto debe mantener una cierta unidad temática, la cual se sostiene por medio de la alusión a algunas entidades textuales básicas. Asimismo, a la par de esta constancia, debe haber algún tipo de progresión informativa. La permanencia de las entidades textuales se produce, en gran medida, por medio de recursos léxicos, introductores, por excelencia, de los temas y de las referencias. Existen diversas estrategias que permiten utilizar el léxico de forma eficaz (economía en el empleo de los elementos lingüísticos) y efectiva (impacto creado en el lector) para 
mantener los referentes: repeticiones, sustituciones por sinónimos o elementos correferenciales en el texto, sustitución por hipónimos e hiperónimos, el empleo de metáforas y metonimias, el uso de calificaciones valorativas, la recurrencia a proformas léxicas y la isotopía.

En cuanto al mecanismo de la repetición, este puede ser una reiteración parcial o total de la palabra o la frase nominal introducida con anterioridad, y se produce por problemas en la memoria de trabajo ${ }^{3}$ para recuperar el referente del que se está hablando, muchas veces debido a la distancia entre la aparición anterior y la referencia actual.

No obstante, la necesidad de la repetición léxica como estrategia para conservar el referente puede perderse cuando la referencia es muy cercana o de fácil recuperación. Cuando esto sucede y el emisor de un texto repite la palabra, el texto se ve afectado en su informatividad (ver 5.3.) y en la sensación de desarrollo temático. Precisamente, los mecanismos de la sinonimia y la correferencia vienen a fungir como alternativas para evitar la mera reiteración de palabras.

En la didáctica de la redacción, se recomienda constantemente no repetir los mismos vocablos cuando estos se encuentren muy cerca, básicamente por una cuestión de estilo: a mayor variedad léxica, mayor calidad del texto. Sin embargo, como lo notan Núñez y del Teso (1996) muy acertadamente, la sinonimia no es un recurso tan flexible y útil como se suele plantear: son pocas las situaciones en las que se puede emplear una acumulación de sinónimos. A este escollo habría que agregar la tan conocida reticencia de los lingüistas contemporáneos a reconocer la sinonimia real absoluta: por lo general, no existen dos palabras que signifiquen exactamente lo mismo y, por consiguiente, no son intercambiables en todas las situaciones comunicativas sin que se modifique el sentido previsto, como se puede apreciar al consultar cualquier diccionario de sinónimos ${ }^{4}$.

Precisamente, Núñez y del Teso (1996) resaltan el valor de la correferencia; es decir, el recurrir a dos o más elementos verbales que designan, ocasionalmente y, en general, dentro de un mismo texto, el mismo referente, como en el ejemplo Gabriel García Márquez y el autor de “Cien Años de Soledad”. En este sentido, afirman que el buen manejo de los mecanismos de uso de la correferencia (forma de elaborarlas y orden de aparición) es muestra de una madurez en la construcción textual. Además, esta estrategia permite crear la sensación de que el texto progresa en cuanto a la información que provee, puesto que se puede utilizar para incorporar nuevos datos, como en el ejemplo: García Márquez publicó recientemente una nueva novela... El premio Nobel de Literatura dijo a la prensa que...

Podríamos afirmar que la utilización de la repetición, la sinonimia y la correferencia es uno de los principales problemas en las redacciones examinadas. El problema es complejo y difícil de sintetizar. Por un lado, los estudiantes repiten el mismo rubro léxico sin variación a lo largo de sus textos, lo cual implica un deficiente manejo de reutilización de la información introducida; esto es, los alumnos no echan mano de lo que han dicho para crear nuevas referencias sobre la misma entidad, como pasa en el siguiente fragmento con las palabras 'problema', ‘alcohólico’ y ‘solución'5.

Plantear un problema actual de Costa Rica es dificil no por falta de ellos sino por su gran diversidad, ya que por desgracia hay una lista enorme de donde escoger pero yo considero que uno de los problemas más importantes es una mala actitud en el nucleo familiar, puede ser una sola persona, despues de todo una manzana mala descompone a todas las del barril, y si se observa el problema de fondo, llegamos a la conclusion de que la sociedad se forma en la familia y si esta está mal que podemos pedirle a la sociedad tomemos como un ejemplo un caso en que el jefe de familia es alcoholico, ahí tenemos el primer problema, alcoholismo, luego como en muchos de los casos el alcoholico puede volverse un agresor, viene el segundo problema que va a ser violencia domestica, este problema podria hasta llegar a convertirse en un 
hijo que recurre a las drogas para huir de sus problemas, este seria el tercer problema, que probablemente no sea ni una tercera parte del problema en sí y sus complicaciones, una verdad es que denunciar o citar, en mi caso estos problemas, es la parte facil, lo dificil es buscar una solución podríamos plantear un sin numero de posibles soluciones, que sé yo psicología terapia o hasta carcel, pero en mi pensamiento es mejor prevenir que lamentar por eso creo que la solución esta con cada quien (....)

Este fenómeno se agrava cuando la falta de variedad léxica interfiere con la correcta identificación de las entidades textuales; por ejemplo, cuando se recurre a un mismo vocablo para aludir a distintos referentes, como sucede en el siguiente párrafo con el término 'personas', en el cual el autor se enfrenta con la necesidad de distinguir los distintos grupos de 'personas', pero recurre a soluciones bastante desafortunadas:

\footnotetext{
Algunas veces las personas no colaboran con las personas que solicitan o mejor dicho piden una ayuda en la calle, por el simple hecho de que temen que su dinero no vaya a ser empleado consturctivamente (sic), es decir, que lo utilicen para comprar alcohol o drogas; pero si hay un proyecto bien elaborado y confiable esto no sucedería y casi puedo asegurar que la mayoría de personas ayudarían (...)
}

Por otra parte, a veces más bien se aprecia una referencia perdida: el término se refiere a un concepto introducido con anterioridad, pero muy lejano en el texto; así, la relación es difícil de entablar y comporta un gran esfuerzo por parte del lector para recuperar la información; o bien, del todo la referencia a la que se hace alusión es distinta o se encuentra ausente. En el siguiente fragmento, 'esta materia' parece referirse a 'valores éticos y morales', pero para la memoria de trabajo representa una fuerte carga en la decodificación:

\footnotetext{
Otro causante de esto es la perdida de los valores eticos y morales esto debido a la influencia de las conductas internacionales y nuestra propia busque (sic) de como estar 'actualizados' esto nos ha influenciado a hacer cosas que no son propias de nuestra cultura. Otra conducta muy arraigada a nosotros es el machismo pues la mujer ha vivido bajo el mandato del hombre lo que produce que ante un abuso se siente temor de de denunciar el agravio o abuso.

Pero todas estas situaciones pueden ser evitadas implantando un sistema educativo donde toda esta materia se fortalezca (...)
}

Al otro extremo, se encuentran casos en los que el emisor del texto emplea palabras con la misma raíz en poco espacio, lo que en realidad muestra su poco manejo de la estructuración informativa y un grave desconocimiento del significado de las unidadas léxicas, además de poca sensibilidad para detectar problemas de estilo:

Es una polémica acarreando con la niñez de nuestros niños

Son pocos los que no toman esa decisión y deciden luchar por lo que es suyo

Otro mecanismo léxico de mantenimiento de la referencia consiste en la consignación de hipónimos e hipérrimos. Los hipérrimos (o hiperónimos) son elementos con significado incluyente, de tal forma que abarcan a sus respectivos hipónimos. Así, 'mesa', 'silla' y 'sofá' son tipos de 'muebles'; en otras palabras, 'mueble' es un término abarcador que comprende los tres anteriores. Se diría, entonces, que 'mueble' es un hipérrimo, que, en un texto determinado, puede tener el valor de permitir una generalización comprehensiva, como sucede en el siguiente caso con el término 'concepto', utilizado para englobar los elementos anteriores:

Podemos decir que la identidad nacional se desarrolla alrededor de elementos de creación propia como el arte, la literatura, la política, las instituciones públicas, la educación, los símbolos nacionales, entre otros, pero el concepto más importante que se maneja dentro de la identidad es el de cultura 
Sin embargo, nuevamente, este mecanismo a veces presenta dificultad para los estudiantes. En el siguiente ejemplo, 'el negocio de extracción de madera' se sustituye apropiadamente por 'acto'; luego, 'circunstancias' parece servir para designar los factores que confluyen en el negocio de la extracción de madera, lo cual sí resulta inapropiado, pues no se trata realmente de circunstancias. El problema textual, por lo tanto, consiste en seleccionar un hipérrimo desacertado, que no subsume los elementos deseados, pues estos no comparten la misma propiedad que queda generalizada por el hiperónimo:

\footnotetext{
En el negocio de extracción de madera son muchos los interesados, y muy pocos los controles ambientales y muchas las vías para evadir las autoridades encargadas de proteger la deforestación.

Muchos de nosotros consideramos este acto como algo degradante para el país y que vamos a hacer algo para cambiar de parecer pero ninguno hace por donde evitar dichas sircunstancias, ni el gobierno, ni los encargados de conservar los bosques, ni ninguno de nosotros y la gran incognita es. ¿Qué podemos hacer para evitar estos constantes problemas de deforestación?
}

Otro mecanismo de conservación del referente es el conocido como elipsis; o sea, la eliminación de alguna porción textual con fines de concisión. En este aspecto, se obliga al receptor a prestar mayor atención para ser capaz de decodificar la información, dado que varias porciones comparten los mismos componentes estructurales. Pese a que la elisión es un mecanismo de suma utilidad y -se diría — indispensable para la economía del lenguaje, en situaciones comunicativas tan desligadas del contexto de producción y recepción, como ocurre con los textos académicos, puede convertirse en un serio obstáculo para la comprensión si no se sabe manejar adecuadamente. La didáctica de la redacción tradicionalmente ha descuidado completamente el tratamiento del tema de la elipsis, quizás porque resulta complicado diseñar "recetas" sobre cuándo es conveniente y cuándo debe evitarse. Sin embargo, la pertinencia de incluir este tema en un curso de expresión escrita se hace patente al examinar el manejo deficiente, por parte de los estudiantes universitarios, de esta estrategia ${ }^{6}$ :

\footnotetext{
El mundo por si solo hoy es ya difícil para las personas que se dicen capaces de responsabilizarse de ellas mismas, ahora para una criatura que no tuvo la culpa de ser concebida sin amor y que aún en este mundo no se le va a recibir se lo merece?
}

\subsubsection{La cohesión a través del mantenimiento del referente por procedimientos gramaticales}

Las lenguas naturales no solamente poseen recursos léxicos para expresar la cohesión textual; también existen una serie de procedimientos gramaticales especializados en indicar que el oyente/lector debe buscar la referencia en otro elemento textual. Estos recursos gramaticales sirven el propósito de descargar el texto de formas de contenido semántico pleno y hacerlo más "liviano" por medio de la señalización de que determinadas entidades discursivas se repiten a través de ciertas marcas: pronombres personales, demostrativos, posesivos, artículos, etc.

La gran ventaja de, en especial, los recursos pronominales consiste, precisamente, en la simplificación del texto, si bien se sacrifica parte de la exactitud del léxico:

(...) en la interacción comunicativa cotidiana se suelen utilizar mecanismos cohesivos que ayudan a economizar o a simplificar la superficie textual, aun a costa de que se pierda cierto grado de determinación (...). Desde este punto de vista, el mecanismo cohesivo, por excelencia, es el uso de las formas pronominales; se trata de elementos lingüísticos de muy corta longitud, económicos, vacíos de un significado propio concreto, que pueden aparecer en la superficie textual en lugar de otras expresiones más definidas y con contenido semántico activo (de Beaugrande y Dressler 1997: 106). 
Para el receptor del texto, estas marcas formales permiten que las referencias se mantengan activas y, a la vez, se evita estar repitiendo las mismas palabras y las mismas estructuras al recurrir a un pronombre que recuerde la información ya introducida. Sin embargo, el mal manejo de este recurso en un texto que no pueda confiar buena parte de su interpretación al contexto puede resultar en referencias oscuras o inexactas. En gran medida, la función comunicativa de la llamada concordancia (sujeto-verbo, sustantivo-determinantes, sustantivo-adjetivo, etc.) y, en general, de la gramática consiste, desde la perspectiva de la lingüística del texto, en mantener la cohesión.

Creemos que, en el fondo, el asunto se ha planteado equivocadamente en la didáctica de la redacción y en el estudio de los problemas de expresión escrita de los estudiantes costarricenses. Cuando, por ejemplo, en un manual para la enseñanza de la redacción se incluye una lección sobre la concordancia y se proponen prácticas de corregir o completar oraciones ${ }^{8}$, se están olvidando dos puntos fundamentales: en primer lugar, que se trata de hablantes nativos que ya han adquirido la gramática del español y que, por consiguiente, difícilmente corregirán sus faltas de concordancia en textos con un método de enseñanza de metalenguaje gramatical, sin mencionar que muchas veces se trata de una cuestión normativa; en segundo lugar, se está enfocando el tema desde una gramática aislada de su función en la lengua (al estilo de la gramática normativa tradicional), cuando lo que corresponde es encauzar la reflexión y la práctica en torno a la función de los recursos gramaticales en la construcción textual. En este sentido, la concordancia no es en sí un problema que tengan los hablantes nativos del español en cuanto a manejo de la gramática de su lengua, sino que se trata de un manejo deficiente de su empleo en la construcción de textos escritos formales y, en especial, de poca conciencia de su valor cohesivo y de una escasa revisión de lo que se redacta. Lo que corresponde, entonces, es practicar la concordancia en textos como un mecanismo para mantener la claridad de la referencia. Mientras el fenómeno se siga estudiando desde su faceta micro aislada (gramática), consideramos que continuarán apareciendo "errores" en un nivel macro (texto) ${ }^{9}$.

Las redacciones examinadas en esta investigación adolecen de muchos problemas de cohesión gramatical. Se podría afirmar que se trata de un problema casi omnipresente en nuestro corpus; únicamente unas quince redacciones están exentas de él.

Existe una discordancia -por lo demás, bastante frecuente- de mínimas repercusiones para la comprensión del texto. Esta falta de concordancia se da, principalmente, entre sustantivos y adjetivos, lo cual revela, a nuestro parecer, descuido del autor y su poca costumbre de revisar lo escrito. En dichos casos, el texto no se ve afectado en la continuidad informativa por cuanto los elementos están muy cercanos o la relación entre ambos es fácil de reconstruir:

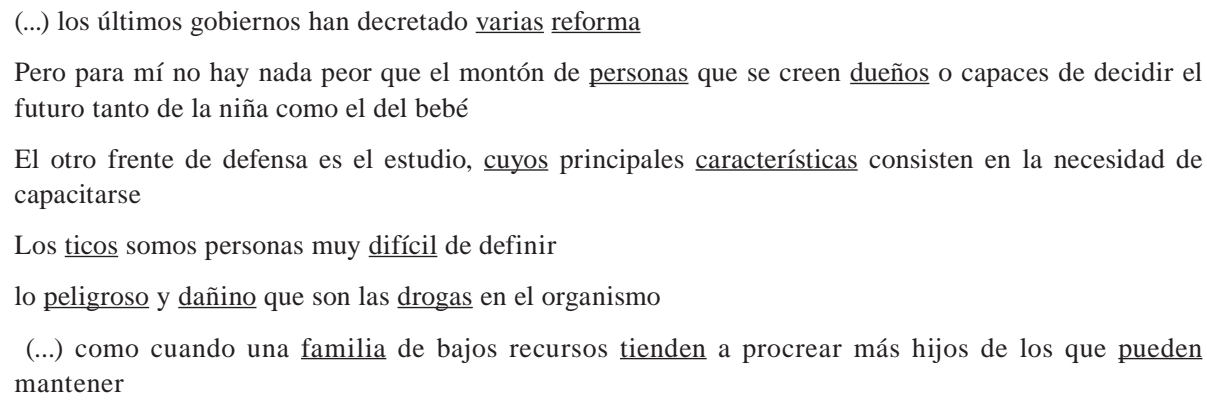


En esta categoría se podría mencionar, asimismo, el caso del pronombre 'le'. Es un fenómeno muy estudiado en el mundo hispanohablante el que se emplee la forma 'le' referida a una frase nominal plural ${ }^{10}$. En nuestras redacciones, el uso de 'le' por 'les' es totalmente común, lo cual desmiente -al menos para Costa Rica- la creencia de que se trata de un fenómeno más extendido en el registro oral que en el escrito. En nuestra opinión, en la gran mayoría de los casos, el pronombre 'le' es redundante ${ }^{11}$, pues acompaña a la respectiva frase nominal que establece la identidad del referente explícitamente; así, se convierte en un mero requisito gramatical, sin un papel relevante en la identificación de cualidades informativamente importantes acerca de las entidades discursivas (por ejemplo, la cantidad, codificada gramaticalmente en español en la categoría de singular frente a la de plural). Por lo tanto, el pronombre 'le/les' no se comporta, en estos casos, como una marca de cohesión necesaria para la correcta decodificación del texto, pues la identidad del referente se aclara en la respectiva frase nominal, que se encuentra muy cerca:

Que mas podriamos decir de un grupo especial de personas que dedican su vida a enseñar a otros mas pequeños e inexpertos los detalles del saber y como hacerle frente a las circunstancias que formaran el entorno de su realidad

También seria necesario que nuestro gobierno no le pusiera tantas trabas a los programas de asistencia social

Nuestra explicación parece más plausible una vez que se analizan casos en los que el pronombre 'le' sí cumple efectivamente una función cohesiva; esto es, cuando la frase nominal correferencial se encuentra lejana y, entonces, este elemento debe mostrar que se trata de una entidad plural que se introdujo antes. En el siguiente ejemplo, la primera aparición de 'le' no concuerda con 'adolescentes', pues es una marca gramatical redundante que no aporta nada; la segunda vez sí aparece la forma concordada 'les' por la lejanía del sintagma correferencial y, sobre todo, porque implica un mayor esfuerzo "llenar" su contenido:

\footnotetext{
Las instituciones gubernamentales, el Gobierno y sus familiares no hacen mucho para darle a estas adolescentes madres una ayuda psicológica, social y económica que les es tan necesaria después de que nace su hijo (...)
}

Por otra parte, se da una discordancia que podríamos llamar de segundo grado, en virtud de la cual sí se produce una lesión en la norma cohesiva. Dentro de esta categoría podemos distinguir casos de muy diversa índole, pero en todos la relación entre los elementos es de reconstrucción más difícil o la discordancia causa una sensación de ruptura en la continuidad y en la conexión de los elementos correferenciales:

En los últimos meses en nuestro país, se ha visto un incremento en los embarazos infantiles. Esto es una realidad muy preocupante que debe llamar la atención de todos los ciudadanos y tratar de resolverlo ${ }^{12}$

(...) ante la falta de una verdadera sociedad donde todos trabajemos como unidad, el problema de narcóticos van a persistir

Los costarricenses no tomamos conciencia de lo que pasa y tranquilamente siguen consumiendo sin ninguna medida el combustible

De todos los problemas que tiene nuestro país el que más me ha llamado la atención es el de que menores de doce años estén embarazadas, sin contar la información brindada por INEC que nos muestran los casos enfrentados por el PANI en tales situaciones con otra cantidad de adolescentes que son madres siendo menores de diecinueve años

No hay comprensión de las personas entre si ya que con costos interactuamos con ella 
Otras veces la discordancia no afecta notablemente la cohesión, pero sí representa pérdida de alguna información. Por poner un caso, en el siguiente fragmento, el pronombre 'lo' y el participio adjetival 'reflejado' no remiten a los tres rasgos del costarricense mencionados, lo cual provoca dificultad en el procesamiento:

La falta de diálogo, la desorganización, el desinterés de y para con los demás, son características propias del TICO. Que lo vemos reflejado en todos los niveles sociales

Lo mismo ocurre en el siguiente párrafo, en el cual el pronombre 'lo' no es claro en cuanto a su referencia, aunque, al devolverse y leer con atención, es evidente que alude a 'hechos violentos':

\footnotetext{
Fundamentando su odio y repulsión en superfluas razones inexistentes cimentadas en un acaparamiento del mercado laboral, es decir, los puestos de trabajo son para emigrantes por que aceptan un salario mas bajo, o porque los hechos violentos son recalcados en los noticieros y prensa cuando una persona extranjera lo lleva acabó
}

El nivel más grave de déficit en el manejo en los mecanismos cohesivos tiene que ver con la inexistencia de un elemento textual que permita llenar la identidad del referente sin equívoco o con la presencia de un referente difuso, difícil de precisar.

No utilizar algún recurso gramatical que haga alusión precisa a una entidad textual introducida puede ocasionar que la conexión entre los elementos se vuelva deficitaria. En el siguiente fragmento, los verbos subrayados se encuentran en plural; el autor recurrió a la elipsis del sujeto, pero resulta difícil saber con precisión quiénes ‘duermen' o 'tienen casas humildes', pues anteriormente se mencionaron muchas entidades ('indigentes', 'niños y ancianos limosneros', 'gente enferma', 'discapacitados'). El autor no aclara, por medio de, por ejemplo, una frase como 'todos ellos', si se refiere a la totalidad de las personas mencionadas o a algún grupo en particular. La misma inespecificidad referencial se encuentra en el pronombre 'les':

\footnotetext{
Estéticamente, a nadie le gusta ir caminando por la calle y observar tanta miseria, indigentes, niños y ancianos pidiendo limosnas en los semáforos, personas durmiendo en cajas de cartón, gente enferma o discapacitada tirada en las aceras, solo por mencionar algunas cosas tan tristes que se pueden ver en nuestras ciudades, más que todo en nuestra capital. Aunque de igual modo sucede en otras provincias, si no es que duermen en las calles, tienen sus propias casas, muy humildes y apenas les alcanza par subsistir.
}

En última instancia, se trata de una elisión mal manejada por el escritor, quien no se tomó su tiempo para verificar las correspondencias entre las entidades de su texto. La cohesión resulta, finalmente, muy dañada, como en el siguiente fragmento, en el que la ausencia de un pronombre englobador 'esto' (o una frase nominal del tipo 'nuestra arrogancia') antes del verbo 'traerá' desconcierta al lector y le resta fluidez a la comprensión:

\footnotetext{
Hay que darnos cuenta de que no somos superiores a nadie solo por nuestro color y que si seguimos así, traera consecuencias más graves para un futuro no muy lejano
}

En el siguiente ejemplo, no es nada claro cuál es el sujeto de 'convertirán'. Por la proximidad sintáctica, se podría pensar en una discordancia con el sujeto englobador 'todo esto'; sin embargo, anteriormente se citaron las entidades 'padres' y 'familiares'. Al leer el fragmento, queda la sensación de que no se sabe con exactitud quién o qué convertirá al niño en delincuente, si bien lo más lógico resulta pensar que toda la serie de circunstancias mencionadas son la causa de la transformación: 
El problema de muchos delincuentes generalmente se da en personas que desde su infancia tienen traumas debido a que sus padres o familiares, peleaban, lo maltrataban, en fin desde que era niño estuvo involucrado en la violencia y no le inculcaron a seguir con sus estudios. Todo esto va causando un impacto en el infante que dentro de unos años lo convertirán en un criminal

A veces, la dificultad reside en la consideración de la autosuficiencia semántica del texto escrito de naturaleza formal, que no puede confiar tanto en la información del contexto para suplir sus vacíos y solucionar sus ambigüedades, como sí se puede hacer en un diálogo coloquial cara a cara. En un texto académico la identidad de las entidades debe ser clara; no es admisible que se oculte o se deje al arbitrio del lector llenar esa información, como ocurre con el referente del verbo 'deberían' en el siguiente fragmento ${ }^{13}$ o con 'manipulan' y 'consiguen' en el segundo ejemplo:

\footnotetext{
Para evitar este problema, deberían de poner penas mas fuertes que castiguen a aquellos que violenten tal derecho como el respeto a la vida

La falta de atención de los padres hacia los hijos producto del trabajo u otras razones impulsa a los adolescentes a querer pasar el día acompañados de sus amigos o alguna persona que les preste la atención que les hace falta, y los padres no se llegan a enterar de lo sucedido en todo el transcurso del día, así es como muchas jóvenes se acostumbran a hacer lo que quieran, y llegan a tener un pensamiento muy liberal, son niñas con pensamiento y comportamiento de mujeres mayores, algunas las manipulan y cuando consiguen lo que quieren las abandonan, en el momento en que algunas de ellas quedan embarazadas llegan haber muchas reacciones
}

Por otra parte, es común hallar en las redacciones una marca gramatical de cohesión, pero esta, en lugar de remitir con claridad a otro elemento para su decodificación, confunde en cuanto a su referencia, como sucede con el relativo 'los cuales' en el siguiente fragmento: ¿cuáles abusos son los peores: los tres o únicamente los psicológicos?:

(...) al hablar de violencia domestica estamos hablando tambien de abusos tanto fisicos como sexuales, psicologicos los cuales a mi parecer son los peores porque de verdad dejan una huella o un trauma muy grande en la persona

El problema de este tipo más recurrente en nuestro corpus guarda relación con el uso de los llamados pronombres neutros; en particular, 'esto' y 'eso'. Estas marcas poseen una referencia general y extensa, con capacidad de englobar porciones textuales de distintas longitudes, a veces muy amplias; de ahí su nombre de anáfora extendida o globalizadora (Calsamiglia y Tusón 2002: 238). Su empleo requiere la precaución especial de que podría no ser preciso cuáles son sus alcances referenciales. Los estudiantes utilizan estos pronombres a diestra y siniestra, sin considerar esta peculiaridad, y en muchas ocasiones incurren en referencias difusas, de muy difícil comprensión y retención para el lector:

Por esto se ha recurrido a los planes de ordenamiento urbano que dicta la ley, pero al hacer esto aparece nuestra problemática: La escasez de planes reguladores de crecimiento, pues muchos de estos han perdido su utilidad o simplemente quedan guardados en las oficinas de los concejos municipales necesitando una actualización.

También se argumenta que esto se debe a la falta de presupuesto de los gobiernos centrales de cada población (...)

La pobreza no solo trae consecuencias un fomento en otros problemas de nuestro país, tal como la prostitución, delincuencia y la drogadicción, ya que las mujeres, niños y adolescentes, al no tener dinero ni siquiera para alimentarse, se ven obligados a vender su cuerpo para subsistir, ya que lo ven como una 
salida fácil. Otros optan por robar, ya que lo consideran una manera sencilla de conseguir dinero. Estas personas se sienten solos, incomprendidos y sin mucho que ganar o perder, no toman en cuenta las consecuencias de sus actos.

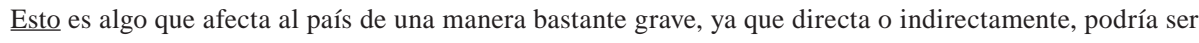
la causa de la gran mayoría de los problemas del país

Por lo general, los problemas comentados no se dan de forma aislada, sino que confluyen en una misma redacción, lo cual, evidentemente, provoca que el texto se perciba como altamente deficiente, poco trabajado e inapropiado para el nivel de instrucción de su autor:

\begin{abstract}
Ultimamente se ha hecho propaganda acerca de esto [el abuso sexual de los niños por dinero] en la televisión demandando a la gente que hace esta actividad, por ejemplo en un reportaje que se mostró hace poco en el país fue el de unas personas españolas que trataron de contactar a las personas que realizan esto para que fueran detenidos por las autoridades y por medio de cámaras los televidentes tuvieron la oportunidad de ver la gravedad del asunto sin embargo muy poca es la que muestra interés o se muestran preocupados por el asunto pero no realizan nada para cambiar la situación
\end{abstract}

Sin embargo, como se comentará más adelante, encontramos, asimismo, redacciones en las que el autor logra utilizar con propiedad los mecanismos de mantenimiento de la referencia, lo que a su vez repercute en la progresión del texto y en su informatividad:

La drogadicción es un gran problema, que está presente en todos los grupos en que se divide nuestra sociedad, sin importar niveles económicos, educativos, edad o sexo.

Y aunque las autoridades han hecho grandes esfuerzos para combatir esta problemática, todos los días se consumen muy variados tipos de drogas. Desde las llamadas lícitas, como el tabaco y el alcohol, hasta los 'cocteles' químicos.

Este comportamiento autodestructivo se puede originar por muchas razones, entre las cuales están: el sentimiento de no ser amado, la depresión, una sociedad permisiva, un ambiente que propicie estas actitudes.

Esta adicción genera consecuencias personales y sociales. Las personales afectan directamente a la persona que consume droga, como por ejemplo: falta de superación personal, problemas familiares, pérdida de la salud, demencia y muerte.

Las consecuencias sociales nos afectan a todos por igual, entre ellas: asaltos, vandalismo y violencia; acciones que muchas veces son realizadas por personas adictas, que están bajo los efectos de la droga. También se da el estancamiento, porque parte de la población no produce y se vuelve una carga para los demás.

Debemos tomar una verdadera conciencia sobre los alcances de este problema y no quedarnos indiferentes. Ya que para combatir la drogadicción lo primero que hay que hacer es denunciar, dejando de lado el miedo, la pereza o el desinterés.

Además se debe apoyar a los centros de rehabilitación para personas adictas, porque muchas veces no tienen dinero ni el personal suficiente, para ayudar a quienes de verdad desean salir de todo eso y superarse.

\title{
5.2. La coherencia
}

Frente a la cohesión, con la que normalmente se la asocia de alguna manera, la coherencia es un concepto más amplio y, muchas veces, algo indeterminado utilizado para referirse al componente conceptual en el texto y su relación con lo extratextual. Así, los textos son coherentes en determinadas circunstancias comunicativas: 
Es un concepto que se refiere al significado del texto en su totalidad, abarcando tanto las relaciones de las palabras con el contexto como las relaciones entre las palabras en el interior del mismo texto. Alude a la estabilidad y la consistencia temática subyacente, asociada a la macroestructura (contenido), a la superestructura (esquema de organización) del texto, a su anclaje enunciativo (protagonistas, tiempo y espacio) y a las inferencias que activan los hablantes para interpretarlo a partir de conocimientos previos (Calsamiglia y Tusón 2002: 221-2).

La coherencia se encuentra en la base misma de la noción de texto como unidad. En principio, todos sus componentes deben guardar relaciones de pertinencia unos con otros para que se interpreten como vinculados, coherentes $\mathrm{y}$, por tanto, pertenecientes al mismo texto. La coherencia entre los componentes de un texto se presenta cuando no existe incompatibilidad o conflicto en la interpretación de uno con respecto a otro y, por ende, el receptor percibe las diferentes partes como compatibles y relacionadas. Habría incoherencia cuando la aceptación de la veracidad de una porción informativa atente contra la aceptación de otra u otras, de acuerdo también con nuestra experiencia y nuestro conocimiento de mundo.

Si la cohesión tiene que ver con la continuidad de los elementos intralingüísticos, la coherencia está más vinculada a la continuidad del sentido en el texto; en otras palabras, los conceptos y las relaciones deben ser relevantes unas para con las otras, e interactuar entre sí para constituir los temas del texto. Los componentes del mundo conceptual del texto son accesibles y no entran en contradicción ni muestran significados ilógicos. La coherencia es una noción compleja en el sentido de que abarca no solo el mundo textual, sino también el contexto, el sentido común, la visión de mundo y los patrones de carácter cognoscitivo por medio de los cuales solemos planificar nuestro comportamiento a partir del reconocimiento de situaciones prototípicas (como pedir la comida en un restaurante o contestar el teléfono). En este sentido, la coherencia no es simplemente una condición de textualidad, sino que más bien revela el funcionamiento de diversos procesos cognoscitivos.

Quizás el problema más grave de coherencia presente en nuestro corpus guarda relación con la incongruencia entre las porciones informativas, la falta de relación patente o la inclusión de fragmentos textuales desarticulados del resto. Muchas veces, lo que se encuentra es una idea poco desarrollada o incrustada en una porción textual que no le corresponde o con la cual no se nota ligada:

\footnotetext{
Es muy triste la realidad en la que nuestra sociedad, se encuentra envuelta a causa de hombres sin escrúpulos y aveces hasta las mismas mujeres con pensamientos absolutamente erroneos, contrarrestando o comparando la forma de pensamiento liberal de la que casi la mayoría de nosotras somos participes
}

En ocasiones, el estudiante incurre en errores de coherencia por problemas en el manejo de la cohesión y por la poca atención prestada a la selección del léxico. Desde la perspectiva de la lingüística textual, las fallas en una norma de textualidad tienen incidencia en los otros estándares, de ahí que un problema de cohesión afecte al mismo tiempo la percepción de la coherencia.

En el siguiente ejemplo, se produce una confusión al no entenderse bien quién es el que no confiesa. Por los indicios textuales (la marca de plural del verbo 'confiesen' parece aludir a 'las personas'; este sería el déficit en el manejo de la cohesión), el lector podría pensar que se refiere a los agresores, pero el fragmento también lo dirige a una interpretación distinta: las que no confiesan son las víctimas. Surge aquí, asimismo, un problema con el léxico: ¿una víctima confiesa?: 
Las personas con que se convive a veces son ellas las mismas agresoras, cuando se ha sido abusada cuesta mucho que lo confiesen, en distintos casos se toma tiempo notar cambios en la conducta y mucho menos cuando los padres no le prestan mucha atención a sus hijos

Muchas veces, es díficil establecer la continuidad necesaria para percibir que se está hablando de "lo mismo". El problema hunde sus raíces, con toda probabilidad, en la poca o nula planificación del texto, concomitante a la ausente revisión del producto final, lo cual provoca que tengamos redacciones en las que el autor anuncia un tema, pero desarrolla otro o coloca ejemplos que no tienen que ver con lo anunciado. En el siguiente texto, el estudiante anuncia que la situación problemática se debe a la actitud de los costarricenses, pero sus ejemplos son de conductas:

\begin{abstract}
Plantear un problema actual de Costa Rica es dificil no por falta de ellos sino por su gran diversidad, ya que por desgracia hay una lista enorme de donde escoger pero yo considero que uno de los problemas más importantes es una mala actitud en el núcleo familiar, puede ser una sola persona, despues de todo una manzana mala descompone a todas las del barril, y si se observa el problema de fondo, llegamos a la conclusion de que la sociedad se forma en la familia y si esta está mal que podemos pedirle a la sociedad tomemos como un ejemplo un caso en que el jefe de familia es alcoholico, ahí tenemos el primer problema, alcoholimo, luego como en muchos de los casos el alcoholico puede volverse un agresor, viene el segundo problema que va a ser violencia domestica, este problema podria hasta llegar a convertirse en un hijo que recurre a las drogas para huir de sus prblemas (...)
\end{abstract}

Incluso hay casos claros de incompatibilidad o contradicción en lo que se escribe. El resultado es un texto oscuro, de difícil comprensión. En el próximo fragmento, el autor se desdice en poquísimo espacio: primero, afirma que no se da bastante información en los colegios; luego, dice que lo único que se hace es enseñar. El conector 'pero' contribuye también a dificultar la interpretación, debido a que no introduce una verdadera oposición entre la porción textual previa y la que le sigue:

\footnotetext{
De alguna manera se le debe de enseñar a las personas a no olvidar los valores que se les han enseñado y tambien el como vivir con ellos y ponerlos en practica en nuestro diario vivir porque en el colegio no hablan bastante de ellos "los Valores" pero de enseñarlos no pasan a mas porque?"
}

El siguiente párrafo también incorpora información incompatible y, por ende, resulta incoherente. Por la forma en que está escrito, pareciera que el estupor del estudiante proviene de que alguien sea condenado por abusar de otra persona, lo cual, con claridad, es incongruente con su tesis:

\footnotetext{
Un aspecto muy importante a destacar en este tema es el castigo que se le impone a los abusadores ya que es increíble que un abusador tenga una condena cuando le esta haciendo un daño permanente a una inocente
}

La colocación de ideas sin conexión interna también está a la orden del día. No solo se trata de que, por ejemplo, un párrafo no continúe con la línea temática o que sea incompatible con lo que se dice antes o después, sino que, además, se hallan casos en los que no hay coherencia en su interior; lo que se encuentra es una sarta de palabras mal dispuestas y sin desarrollo. El siguiente fragmento es un párrafo independiente en una redacción sobre el embarazo en adolescentes; en él se puede apreciar la incompletud de sentido por la deficiente construcción sintáctica:

En cuanto a la madre, que si no decide abortar a su hijo poniendo en peligro hasta su vida misma, decide tenerlo, pero que grado de afectividad irá a recibir el pequeño durante su niñez. 
Como lo hacen notar muy acertadamente Núñez y del Teso (1996), la incoherencia puede constituirse en el problema más grave de construcción de los textos en tanto interfiere con su interpretación ${ }^{14}$. Sin embargo, los errores de este tipo no suelen ocurrir porque el hablante no discierna la incompatibilidad semántica en un nivel profundo, sino por problemas en el manejo del léxico, tales como un conocimiento insuficiente o errado del significado real de las palabras en contextos específicos y el uso poco pensado del vocabulario por emplear. Así, las incoherencias surgen cuando las implicaciones reveladas por las palabras empleadas son conflictivas con el resto del texto o introducen conceptos "extraños".

No obstante lo anterior, se acepta la existencia de la llamada presunción de coherencia (Brown y Yule 1993, Calsamiglia y Tusón 2002), según la cual los hablantes se esfuerzan por encontrar el sentido (relación y pertinencia) de los enunciados que se presentan como conformadores de un mismo texto a partir del contexto en el que se produce y no se centran en el significado absurdo e ilógico que, en apariencia, tienen. Por ejemplo, en una soda universitaria se encontraba el siguiente anuncio: "Le preparamos ensalada de frutas con yogurt/ gelatina y bistek encebollado". Por el orden sintáctico, quizás una persona quisquillosa, o particularmente propensa a ocasionar problemas, exigiría que su ensalada de frutas contenga, además de la gelatina, el bistek anunciado. Sin embargo, este comportamiento no sería el más esperable, en vista de que los clientes de dicha soda normalmente interpretarían que el bistek encebollado no va con la ensalada de frutas, sino que también se prepara separadamente a petición del cliente. Este mismo principio aplica cuando nos encontramos en un periódico con los gustados ejemplos de anfibología de los manuales de redacción: "Se venden colchones para niños de resortes".

En todo caso, a pesar de que es de esperar que la presunción de coherencia actúe automáticamente en todos los casos, un texto de carácter académico, formal, bien planificado - como los que se solicitan en la educación universitaria— no debería presentar tales usos, pues no se supone que se deba confiar en la actitud cooperativa del receptor para tales efectos. En nuestro corpus, este tipo de construcciones no aparecen con frecuencia, pero, cuando lo hacen, resulta una información extraña, por lo usual fácilmente interpretable, aunque inapropiada para un ensayo de esta índole. En el siguiente fragmento, por la sintaxis, pareciera que los niños son quienes carecen de trabajo y de casa:

Hoy en día los divorcios están a la vuelta de la esquina. Este problema por lo general tiene como conse-
cuencias niños abandonados sin hogar, o madres con niños sin empleos y un techo donde criarlos

Núñez y del Teso (1996: 149) apuntan que "el uso irreflexivo del lenguaje, particularmente en redacciones escolares, está muchas veces vinculado a la 'insinceridad' de la redacción. Los estudiantes recurren con frecuencia a palabras y frases hechas, que ellos asocian con el nivel de redacción que se les pide, sin apropiarse de ellas como usuario, de manera que se utilizan en el texto con una conciencia débil de la información que realmente se está introduciendo" (Núñez y del Teso 1996: 149).

En nuestro corpus, esta afirmación se evidencia contundentemente. Las redacciones están llenas de usos léxicos extraños y confusos. A todas leguas, se nota que el estudiante realmente no conoce el significado de la palabra o el sentido de la combinación de varios vocablos (fraseología) o posee una vaga idea de la expresión pero desconoce la exacta combinación léxica. Este constituye, sin duda, el problema de coherencia más recurrente, si bien se trata de un déficit de menor nivel que los comentados, pues resulta fácil reparar el daño. 
En primer lugar, los ejemplos de combinaciones inapropiadas son abundantes. Se trata, en estos casos, de emplear palabras que normalmente no van ligadas, pues su semántica es incompatible: $\mathrm{Y}$ es que concientizar a estas personas es muy díficil, ya que se debe adquirir un gran empeño por
parte de la población y principalmente del gobierno para que brinde ayuda económica [¿los empeños se
adquieren?]

La necesidad de formarnos universitariamente ha sido un hecho que más y más estudiantes han puesto en práctica, ya sea para solventarse económica, social o intelectualmente [¿la necesidad se pone en práctica?, ¿uno se "solventa" de estas maneras?]

Este problema es muy difícil de desenvolverlo, ya que está compuesto por muchos factores, que dependen a la vez de muchas personas, incluyendo a todos los conductores [¿los problemas se desenvuelven?]

En segundo lugar, se hallan ejemplos de desconocimiento del significado real de las palabras. El estudiante en realidad ignora la semántica exacta del vocablo, así que lo utiliza con un valor aproximado:

(...) cabe resaltar que generalmente las niñas que son agredidas pertenecen a clases marginales donde el nivel económico y educativo es muy bajo y por tanto sus ciudadanos [habitantes] resultan de alguna manera, incapaces de tener alguna noción sobre el daño (...)

En los últimos años Costa Rica ha sufrido por un problema que a todos como parte de una sociedad no nos afecta directamente, pero si es una molestia que degrada la moral de los Ticos, ello es el la fecundidad [fecundación, embarazo] en niñas y mujeres preadolescentes

Estos servicios, los cuales no todos aportan económicamente [pagan] los inmigrantes (servicios de salud, educación, seguridad, ect.) sus costos deben ser sufragados por el gobierno central. Esta problemática de abastecer servicios no cobrarles en muchos casos, tiene indicaciones [implicaciones] directas en el déficit presupuestario y por lo tanto implica grandes incrementos a la deuda interna

El desinteres por los demás, los problemas que las demás personas pueden estar pasando en sus vidas y los problemas que acojan [aquejan] a la sociedad (...)

Este desconocimiento podría ser la principal causa de las llamadas tautologías. El estudiante ignora el significado preciso de una palabra, pero la ha escuchado y la asocia con un tema concreto, así que echa mano de ella al redactar un texto con un tema igual o cercano; no obstante, repite la misma idea porque no se percata de que -con distintas palabras o giros- está expresando en esencia lo mismo:

Ellos se enfrentan, primero, a problemas como la venta de drogas ilegales entre estudiantes, así como, problemas académicos tales como deserción y abandono escolar que crea patrones delictivos en los adolescentes (...)

Por último, es evidente el descuido absoluto en el uso de las palabras, de forma que se termina diciendo algo distinto a lo planeado o, de plano, algo contradictorio. Por consiguiente, la coherencia se ve afectada:

En el negocio de extracción de madera son muchos los interesados, y muy pocos los controles ambientales y muchas las vías para evadir las autoridades encargadas de proteger [evitar] la deforestación

Hoy día vemos en todos los medios de comunicación como hay mujeres maltratadas o mejor aún, [peor aún] abusadas física, psicológica o incluso sexualmente por su pareja

Hace aproximadamente unos 50 años, Costa Rica era un paisaje de belleza natural. Su totalidad, reflejaba mantos verdes, sabanas extensas donde habitaban millones de distintas especies. Los ríos estaban colmados de vida marina [acuática] y vislumbraban [mostraban] la pureza del lugar 
En suma, los problemas en el manejo de la norma de coherencia por parte de los universitarios aquí estudiados se evidencian en dos aspectos: la deficiente planificación que los lleva a introducir ideas o fragmentos textuales inconexos, irrelevantes o incompatibles; y el descuido en la selección de las palabras, causante de incongruencias, contradicciones y giros extraños.

\subsection{La informatividad}

La informatividad "se relaciona con el grado de novedad o de imprevisibilidad que tiene un texto para sus receptores" (de Beagrande y Dressler 1997: 201). La informatividad se valora a partir del contenido expuesto y depende, en gran medida, de los destinatarios del texto. Además, en principio implica una mayor carga en el procesamiento del mensaje, lo que tiene repercusiones para que un texto se conciba como más o menos interesante. Esta norma también se relaciona con el grado de probabilidad o previsibilidad del contenido; cuanto más previsible sea lo dicho, menor es la informatividad del texto y, por consiguiente, recibe menos atención, como sucede con las palabras funcionales (artículos, conjunciones, preposiciones), las cuales no aportan mucho al contenido y son tan frecuentes que, por lo general, pasan inadvertidas y no se recuerdan.

Se podría entender la informatividad, asimismo, como la pertinencia de los elementos incorporados en el texto, con lo cual vincularíamos este estándar con el de la coherencia. Siguiendo a Núñez y del Teso (1996), la pertinencia hace que las partes de un texto sean relevantes en relación con otras partes y con el todo. Consideramos que la pertinencia es un factor relacionado con la informatividad por cuanto esta última se ve afectada si un emisor incorpora en su mensaje elementos irrelevantes que hacen perder la atención y el interés de los destinatarios con respecto a lo que se dice.

El manejo de la informatividad no es sencillo. Los receptores esperan que se les diga algo "nuevo", que conforme avanza el texto se les provea de material novedoso, pero difícilmente aceptan que la información sea excesivamente novedosa y, por lo tanto, de una comprensión que demande mucho esfuerzo de atención y procesamiento.

\footnotetext{
Un texto bien construido debe instalarse adecuadamente en esa tensión entre la expectativa de que habrá información añadida y la resistencia a que la información nueva represente un añadido brusco que rompa la unidad. Ante un texto abrupto, en el que los datos nuevos se suceden a saltos y sin una continuidad perceptible, el receptor será incapaz de advertir el propósito de los enunciados componentes y, por tanto, resultará anómalo porque no se percibirá pertinencia entre sus partes (Núñez y del Teso 1996: 158).
}

A nuestro parecer, la informatividad es una de las normas textuales más dañada en las redacciones examinadas. Las deficiencias son múltiples: van desde el uso de elementos poco informativos o sin pertinencia, pasando por constantes digresiones que interfieren en el desarrollo del hilo expositivo-argumentativo, hasta una total desconexión entre las porciones textuales. La vaguedad con la que se tratan los temas y el volver una y otra vez sobre el mismo asunto sin aportar elementos nuevos son frecuentes.

La primera deficiencia en la informatividad se encuentra en el empleo recurrente y poco meditado de un hipérrimo de significado muy amplio para referirse a un conjunto de elementos que guardan entre sí alguna relación en la realidad o en el universo textual; usualmente, se trata del vocablo 'cosa'. 
Nuevamente, el tema de la inconveniencia de emplear palabras como 'cosa' en las redacciones se plantea equivocadamente en la didáctica de la expresión escrita: como parte de la sección de vicios del lenguaje bajo la etiqueta de 'cosismo'. En los manuales de redacción, no se le suele indicar al estudiante cuál es el problema de recurrir al vocablo 'cosa', sino que simplemente se incluye una definición vaga: "Cosismo: Consiste en la utilización de la palabra 'cosa' (en el caso de los costarricenses también usamos el vocablo 'chunche') para remitir a cualquier situación u objeto” (Varela y Sandino 1993: 77). Como se puede apreciar, por la definición, no es evidente ningún problema; en efecto, 'cosa' y 'chunche' son palabras de significado extensivo capaces de ser usadas para remitir a referentes de muy diversas índoles, concretos y abstractos. Es difícil comprender, por consiguiente, por qué no se debe usar.

Otras veces, el asunto se presenta lleno de prejuicios y revela la insuficiente formación lingüística de los autores de dichos manuales; así, refiriéndose al cosismo y otros "vicios" semejantes, otras autoras afirman: "La imprecisión es un vicio que se comete por descuido y exceso de pereza mental; es decir, que se recurre a un término impreciso por pereza de pensar, pronunciar o escribir el nombre o verbo propio del objeto o de la acción" (Pacheco y Álvarez 1997: 65).

En realidad, 'cosa' -y otros términos parecidos, a saber: chunche, asunto, elemento, etc.- son proformas léxicas ${ }^{15}$ con las que cuenta el idioma para hacerles frente a las demandas de la producción lingüística sobre la marcha, en situaciones altamente dependientes del contexto. Generalmente, cuando hablamos, el contexto compartido con nuestro interlocutor nos permite ser menos explícitos, menos exactos en las referencias, como aludir a los muebles de la sala, la ropa lavada que está en el sillón, los recibos por pagar y varios libros por medio de la emisión “¿Qué montón de cosas hay aquí!”. Con ello, no mostramos pereza mental ni ningún déficit en nuestro desarrollo cognoscitivo, sino que sencillamente recurrimos a una estrategia de vaguedad del término porque la naturaleza del refererente es clara pero muy difusa, con lo cual podemos continuar con una comunicación fluida pese a la planificación y la producción inmediatas. Por el contrario, cuando se escribe, no solo se cuenta con mayor tiempo para planificar el mensaje, sino que -a menos que los interlocutores tengan mucho conocimiento del tema- además se puede confiar menos en el soporte del contexto. Por ello, se requiere recurrir a palabras con un significado más intensivo, menos amplio, lo cual resulta posible gracias a que se cuenta con más posibilidades de buscar la palabra precisa, de revisar la estructura sintáctica y de meditar las estrategias para lograr nuestros fines de manera exitosa.

Nos hemos extendido en este punto, dado que nos parece que es un ejemplo claro del cambio de perspectiva que se debe suscitar en nuestro medio en torno al diagnóstico de las deficiencias en la expresión escrita de los estudiantes y, especialmente, en relación con la didáctica de la redacción. El enfoque purista que se queda en la etiquetación de un fenómeno o que se desvía en valoraciones acientíficas y elitistas no conlleva ni a la comprensión de este ni -lo que es peor- a su solución.

Desde nuestra perspectiva discursiva, el problema con el empleo de la palabra 'cosa' y otras semejantes en textos escritos académicos yace, más bien, en su bajo nivel de informatividad: en vista de que se comporta como un hipérrimo para una innumerable cantidad de campos semánticos, no aporta un significado exacto ni le ayuda al lector del texto a catalogar las entidades discursivas con precisión. Esto, a fin de cuentas, repercute en la calidad de la información que provee un texto. Asimismo, enfocándolo de otra forma, el referente no es claro, por lo cual es un problema también de cohesión: 
Una de las cosas que llevan a un embarazo no solo es la irresponsabilidad de los mismos jóvenes sino también la falta de atención de los padres hacia los hijos (...)

Pero claro no todo es malo siempre podríamos recordar algunos presidentes que si han hecho cosas buenas por el país, algunas modificaciones en ciertos Ministerios, buenas construcciones y algunos avances en tecnología.

La mejor manera que se puede sugerir, es que si no se ha estado haciendo las cosas como se deben o de la mejor forma; el momento para cambiarlo es ahora. Es el momento de levantarnos y caminar hacia el progreso, de decidir que seremos diferentes, que de ahora en adelante tendremos la metodología correcta.

Pero, ¿cómo lograrlo? Buscando ayuda de colegas que han surgido de sistemas diferentes, que puedan darnos una perspectiva de las cosas de la que nunca habríamos visto (...)

Las fallas en el manejo de la informatividad no se presentan con exclusividad en un nivel léxico, como el recién comentado, sino, sobre todo, en el nivel de la construcción del texto como totalidad, en la ligazón de las partes con el todo. Algunas veces, el problema se encuentra en la apertura o el cierre del texto. Los textos deben ser semánticamente autosuficientes, deben sentirse como una unidad completa, razón por la cual cada una de las partes debe contribuir a esta completud en alguna medida. Además, el componente de novedad -de vital importancia para esta norma de textualidad- debe manejarse con cautela: la progresión informativa debe ser paulatina, de modo que se le ayude al lector ubicándolo primero en el meollo del asunto para luego hacerlo avanzar en los detalles, argumentos, pruebas, etc.

En el siguiente ejemplo, nos encontramos ante un comienzo abrupto, dependiente del título para poderse entender. Deja, por tanto, una sensación de que algo falta, de que en realidad no hay introducción. Siguiendo a de Beaugrande y Dressler (1997: 258), "los aspectos más informativos de un tema, es decir, los más aptos para recibir un desarrollo que pueda interesar a los receptores, son aquellos que incluyen problemas y variables, es decir, cuestiones abiertas y opinables que aún no han sido establecidas definitivamente porque están sujetas a cambios y plantean problemas todavía no resueltos". En este sentido, el gran problema del siguiente texto es que el autor entra de una vez en el tema con una pesada carga de informatividad:

\footnotetext{
La falta de cultura del costarricense

Cuando hablo de cultura, no me refiero a la cultura general que se adquiere en el colegio, universidad y en otras fuentes como textos; en cuanto a cultura me refiero a la educación, modales y el aspecto moral con el que nos desenvolvemos todos los días. Como reaccionamos a los problemas nacionales e internacionales y sus posibles soluciones, es algo que el tico, en su mayoría, deja mucho que hablar.
}

El déficit también puede estar en el final del texto. En estos casos, sucede lo mismo que lo comentado anteriormente: el final se torna abrupto, así como pesado en términos de informatividad: se deja para el cierre una carga de información alta, información que resulta sorpresiva por su poca previsión. En el siguiente ejemplo, el autor parece estar hablando del problema del desempleo, pero termina sorpresivamente con una serie de ideas relativas a las universidades privadas. No es que no haya relación entre las porciones textuales, sino que se deja para el final una cantidad muy alta de información, la cual, como consecuencia, no se desarrolla. Asimismo, el deficiente manejo de la información es patente a lo largo de todo el escrito, en el que se esbozan muchas ideas pero no se desarrollan: 
La necesidad de formarnos universitariamente ha sido un hecho que más y más estudiantes han puesto en práctica, ya sea para solventarse económica, social o intelectualmente.

Es debido a esto que ha aumentado la demanda en cuanto a matrícula en las universidades, tanto estatales como privadas, provocando a la vez un gran número de profesionales.

El exceso de profesionales ha causado grandes problemas, y quizá el más importante, el abaratamiento de la mano de obra y el aumento en los índices de desempleo.

Es de entristecerse cómo médicos, luego de estudiar y prepararse por varios años no pueden realizar su práctica y tienen mientras esperan su turno laborar en otros oficios.

A la vez estos problemas generan má problemas sociales como lo son la drogadicción, prostitución, bandalismo, robos y muchos otros más.

Hay que ponerle un alto a esta situación en donde las universidades privadas han jugado un papel muy importante, deberían de poseer un mayor control en cuanto al número de personas que ingresan y enfocarse mayormente a la calidad y no tanto a la cantidad de éstas, para el bien de todos nosotros como futuros profesionales y forjadores del mañana.

Muchas veces, los textos están compuestos de varios subtemas, pero deficientemente engarzados, lo que provoca que en realidad parezcan temas sin relación y se vea afectada la percepción misma de la unidad. En estos casos, la informatividad se halla fuertemente dañada, tanto porque el componente de novedad es demasiado abrumador, como porque la pertinencia de cada fragmento no queda clara en absoluto. En el siguiente ejemplo, se pasa de la pobreza a la disminución de la clase media, la migración, los homicidios, hasta la prostitución, en escasas dos páginas:

La pobreza en nuestro país ha sido un problema que en los últimos años ha estado en constante aumento. Este lamentable y serio problema hace a nuestra nación ser uno de los países con más alto porcentaje de pobreza a nivel mundial. Pero ¿qué hace el gobierno para solucionarlo?

Lo más lamentable de este asunto es el poco o regular interés que muestra el Estado por las familias que viven en extrema pobreza en nuestro país, ellos creen que con el simple hecho de donar unas viviendas o organizar unos cuantos proyectos van a solucionar un problema tan grave, si es una buena alternativa pero no la única solución.

En nuestro país la llamada clase media cada vez es menor, miles de familias viven en condiciones de miseria, donde no tienen donde vivir, que comer, con que vestirse y cada vez hay más tugurios, la marcada división de clases cada vez es mayor, mientras unos tienen cada vez menos otros tienen más y más, pero que podemos hacer si la calidad de vida va en descenso, si los precios de los productos cada vez son más elevados y la economía nacional está estancada, la pobreza es mayor y no hay prontas ni buenas soluciones.

Muchas veces también la pobreza puede ser la causante, pero no la justificante en cierta medida de otros problemas que se presentan en el país como la alta migración, donde el caso más marcado es exagerada cantidad de nicaragüenses que llegan a nuestro país, otro ejemplo muy claro es la migración de los guanacastecos y los habitantes de la zona norte a la región central del país, con el único fin de buscar y tener mejores condiciones económicas para lograr salir de miseria en que se encuentran.

Otro punto importante es la cantidad de homicidios que comenten en el país, aunque no es una justificación muchas veces algunas personas por el simple hecho de tener que conseguir dinero para su familia, llegan al extremo de matar a una persona por quitarle alguna cosa de valor.

Otro asunto de gran relevancia es el hecho de que la pobreza conlleva a las familias a tener que prostituir a sus propios hijos para salir de las malas condiciones económicas en que se encuentran.

Una posible solución realmente importante es que se debe poner en práctica es la de buscar fuentes de empleo para las personas que se encuentran en una situación de pobreza extrema o suministrar mayor educación a estas familias para tener un trabajo digno. 
Pienso que debemos hacer conciencia de encontrar prontas soluciones a un problema tan grave que no es de una persona o de una familia sino de todos los habitantes que vivimos en nuestro país ya que si esto continua de esta manera el país va entrar en bache económico que lleva a la decadencia de todos sus ciudadanos.

Los problemas de informatividad, de pertinencia y de coherencia son graves. Están presentes, en mayor o menor medida, en la práctica totalidad de las redacciones examinadas. En gran parte de los casos, la norma de informatividad se encuentra seriamente dañada por los problemas de sintaxis y de léxico, pero también por la argumentación, llena esta de contradicciones e ideas mal planteadas. El siguiente texto ${ }^{16}$ adolece de argumentos débilmente presentados $(\$ 2,6)$ y ejemplos extraños; el autor se contradice constantemente (\$7) y no tiene reparos en explicitar sus prejuicios (§4). El texto, en suma, muestra la poca madurez en la construcción textual que se evidencia en muchos estudiantes universitarios:

(§1) “Tiene usted algún familiar, amigo o conocido que haya venido para buscar una mejor calidad de vida, libertad de expresión? El porcentaje de inmigrantes en nuestro país aumenta cada día más, causando que la población crezca sin ninguna planificación. Costa Rica está viviendo una serie de problemas socioeconómicos los cuáles no ha encontrado solución que varios son causados a la gran demanda que hay de inmigrantes en nuestras tierras.

(§2) Costa Rica está viviendo un incremento sobrenatural en el tamaño de su población . Este incremento resultado de la inmigración de principalmente latinos, por diversas razones, aplica grandes presiones al sistema de salud, educación, vivienda, seguridad, abastecimiento de servicios básicos (agua potable, electricidad, recolección de basura y aguas servidas). Estos servicios, los cuales no todos aportan económicamente los inmigrantes (servicios de salud, educación, seguridad, etc.) sus costos deben ser sufragados por el gobierno central. Esta problemática debe abastecer servicios no cobrarles en muchos casos, tiene indicaciones directas en el déficit presupuestario y por lo tanto implica grandes incrementos a la deuda interna .

(§3) Ante lo anterior no toda la población costarricense le da la bienvenida a los inmigrantes por sus implicaciones que tienen en impuestos, faltantes de cupo en el sistema educativo, demanda excesiva y largas filas para ser atendido en servicios de salud. Por otro lado la población excesiva crea una sobre oferta en mano de obra; la necesidad de trabajar por los inmigrantes casi los obliga a trabajar por menos, cuyo resultado es un desplazamiento de la mano de obra tica (que cobra los mínimos o más) dejando parte de la oferta sin trabajar. Así mismo los extranjeros toman los trabajos más básicos o menos remunerados desplazando a los ticos a la necesidad de competir por trabajos que requiere mejor educación o experiencia, lamentablemente no siempre tienen estos requisitos.

(§4) Otro problema es la perdida de la cultura propia del tico por tradiciones extranjeras. Hoy en día es muy común encontrar ventas de vigorón y la gente comiendo con los dedos por todo lado. Esta perdida de identidad tica nos acerca cada vez más a las características propias de una urbe, donde los principios, benevolencia, solidaridad, etc. produce un comunidad más fría, individual y aislada.

(§5) Ante la inmigración la necesidad de crear una comunidad de países latinoamericanos que se ayuden en aspectos políticos, tecnológicos, didácticos, etc, crean una región con igualdad de desarrollo en lugar de países aislados donde las poblaciones no tengan que trasladarse en busca una mejor calidad de vida.

(§6) Otra forma de ayudar es brindándoles educación en Costa Rica. De este modo los formaríamos intelectualmente y estarían mejor capacitados para trabajar. Los índices de analfabetización disminuirían y la población tendría una mejor calidad de vida. También con la salud, así la tasa de mortalidad se disminuyeran. El desarrollo de Costa Rica no se vería afectado y tendría un desarrollo constante que sería de buena ayuda para los problemas socioeconómicos costarricenses.

(§7) No deberíamos darle la espalda a esta situación si no ver cómo se soluciona lo más pronto posible. Así si algún día necesitamos de su ayuda, nos la darían. ¿Adónde está la solidaridad, la hermandad y el compañerismo? 
Sin embargo -justo es reconocerlo-, el diagnóstico realizado se ha concentrado en las redacciones deficientes, aunque se encuentran, del mismo modo, textos con un muy buen manejo de la textualidad, como el que se transcribe a continuación, escrito por un estudiante de ingeniería, por aquello de que la profesión elegida no es justificación para no saber escribir con propiedad:

Durante nuestro proceso educativo, nos encontramos involucrados con una amplia gama de tópicos, los cuales relacionamos con las ciencias básicas. Através de este proceso entramos en contacto con la física, la química, la biología y la matemática. De estas, la matemática es la ciencia más temida por los estudiantes tanto de secundaria como de la universidad. En nuestro país, se ha generalizado un fobia hacia las matemáticas, que inhibe a los estudiantes y muchas veces los conduce al fracaso. Estudios realizados, demuestran que esta fobia afecta el número de profesionales en las carreras técnicas, ya que los estudiantes huyen de las matemáticas; vitales en profesiones como la ingeniería o la arquitectura. Además, esta fobia hace que los estudiantes deban repetir sus cursos de matemática varias veces antes de aprobarlos. En la Universidad de Costa Rica, lo anterior se refleja en el número de repitentes en materias como Cálculo o Álgebra Lineal. Este es un verdadero problema para nuestro país.

Esta fobia hacia las matemáticas, se ha desarrollado por factores internos y externos al proceso de aprendizaje de las matemáticas. Factores externos como presión familiar y una cultura la cual estigmatiza a las matemáticas de ser la materia más dura durante el proceso educativo. Muchas veces los padres de familia son los encargados de estigmatizar a las matemáticas basados en sus propias experiencias negativas, e inclusive se encargan de justificar los fracasos de los estudiantes. Estos padres de familia aluden a la realidad nacional, de que la matemática es la materia que presenta los resultados más bajos a nivel de noveno año y bachillerato. En mi opinión, este comportamiento únicamente fortalece la mediocridad que impera en el sistema educativo y en la sociedad costarricense.

En el ámbito interno del proceso del aprendizaje de las matemáticas, el estudiante también es víctima de una variedad de elementos negativos que entorpecen el proceso de aprendizaje. Tales elementos incluyen al profesor y a los compañeros. Existen algunos docentes que atemorizan a sus estudiantes. Varios estudios de la Universidad de Boston demuestran que este tipo de comportamiento docente inhibe al estudiante y poco a poco se fomenta la fobia hacia las matemáticas. El país además cuenta con un número muy limitado de profesores de matemática acreditados por alguna universidad. Esta carencia también es otro factor que afecta este proceso de aprendizaje, ya que el proceso demanda profesionales capacitados.

Además de los factores ya mencionados la convivencia con otros estudiantes puede desfavorecer el aprendizaje de las matemáticas. Generalmente, la opinión de la comunidad estudiantil posee una posición negativa hacia esta materia, la cual facilmente propagan por todo el estudiantado.

Esta problemática no presenta una solución inmediata, ya que el problema se ha gestado durante bastantes años. En mi opinión, el problema debe ser atacado mediante tres frentes.

Primero, debe de hacerse un llamado nacional para corregir la visión que se tiene acerca de las matemáticas. Se debe de educar a la sociedad de que las matemáticas no son difíciles y que cursos como Matem 125 y Cálculo no son imposibles de aprobar. Este proceso requiere de varios años, ya que la educación de un pueblo no puede modificarse de la noche a la mañana.

Además de esta medida el país debería fomentar la revisión de los programas de educación en primaria y secundaria. Si se evaluaran temas de mayor relevancia a nivel de bachillerato, los estudiantes estarían mejor preparados para enfrentar cursos como Calculo y Algebra lineal.

Por último el tercer instrumento para hacer frente a este problema es un cambio en la metodología en la enseñanza de la matemática. El docente debe asumir otro rol, y debe de moldear en el estudiante un aprecio por las matemáticas.

Este conflicto no es fácil de solucionar ni mucho menos rápido de corregir. Como lo he mencionado con anterioridad, todos somos parte del problema, por lo que debemos colaborar con la solución. Es vital que todos nos unamos a esta causa en pro del desarrollo de nuestro país. El país necesita de ingenieros en todas las áreas y no podemos permitir que esta fobia afecte el número y la calidad de nuestros profesionales. Yo como futuro ingeniero civil estoy conciente de mi compromiso con el desarrollo del país y con la solución de este problema, ya que nos concierne a todos. 


\section{Conclusiones}

Los aportes realizados por las investigaciones previas a la nuestra siguen vigentes. Efectivamente, las redacciones aquí estudiadas muestran muy poca conciencia por parte de sus autores de los rasgos propios de la escritura formal y de la oralidad coloquial; por lo general, la primera se halla invadida por características de la segunda. Asimismo, el problema es mucho más profundo: los estudiantes no manejan las estrategias propias del registro escrito, las subutilizan o de plano las desconocen. Los años de escuela y colegio no parecen haber ayudado a madurar el uso del cógido de forma competente.

Nuestro aporte consiste en haber llamado la atención sobre el valor de la perspectiva que se asuma a la hora de analizar las deficiencias de redacción. Si estamos hablando de la calidad de los textos, debemos observar sus problemas y sus aciertos como textos; esto es, en cuanto a su constitución como unidades semántico-pragmáticas de la comunicación cuando los participantes no se encuentran en una relación cara a cara ni inmediata, lo que implica que no se puede descansar en el contexto compartido para llenar los vacíos y despejar las ambigüedades.

Desde nuestro punto de vista, entonces, los textos examinados no solamente presentan problemas en el manejo de la morfosintaxis, el léxico, la puntuación o la ortografía de la lengua, sino que sus mayores déficits -los más relevantes si lo que evaluamos es su calidad de textosson de naturaleza textual; en particular, nos detuvimos en este artículo en tres normas de textualidad: la cohesión, la coherencia y la informatividad. Las tres se muestran profundamente dañadas por el deficiente empleo de las unidades micro (v.g. mala subordinación, palabras equivocadas), pero también por la organización del texto como unidad. En este sentido, no parece existir una clara conciencia de la cohesión como estrategia de ligazón y de esclarecimiento de la identidad de las referencias; de la coherencia y las incongruencias, incompatibilidades o contradicciones; ni de la informatividad y el manejo de la novedad y de la progresión temática de lo que se escribe. El problema, por ende, es de índole especialmente discursiva y de poca práctica en el proceso de construcción textual (planificación, elaboración de borradores y revisión).

Sin pretender dar una explicación definitiva, creemos que una buena parte de la responsabilidad de los problemas textuales encontrados recae sobre la concepción misma de la didáctica de la expresión escrita. Como lo comentamos extensamente en otra parte (Sánchez Avendaño a), el enfoque gramatical-purista de nuestra enseñanza lingüística escolar se ha obsesionado con la cacería de la diversidad de usos idiomáticos -opuesta por definición a su interés homogeneizador y elitista de la lengua- y se ha dedicado a tratar de erradicar los empleos considerados como incorrectos desde una perspectiva acrítica y alienada. El desarrollo de las destrezas comunicativas, como consecuencia, ha sido tradicionalmente relegado o mal enfocado, calificando a los estudiantes de perezosos mentales y de bárbaros xenófilos.

Como se puede apreciar, la gran diferencia de nuestro análisis frente a uno de naturaleza normativa se evidencia en nuestra posición frente a fenómenos tradicionalmente incluidos en los manuales para la enseñanza de la redacción como solecismos, anfibologías, tautologías y vicios idiomáticos en general. Creemos haber mostrado que, por ejemplo, la etiquetación de los elementos considerados deficientes en la expresión escrita de los alumnos y su calificación de formas viciosas no solo podría promover inseguridad en los discentes, sino que, sobre todo, no resuelve ni aclara en nada el problema. Así, por ejemplo, considerar 
la inadecuación del uso de la palabra 'cosa' por su bajo nivel de informatividad y explicitud, o de las discordancias gramaticales por las dificultades en el establecimiento de la identidad referencial de las entidades discursivas nos ha parecido un enfoque más esclarecedor del problema y más respetuoso del estudiante.

\section{Notas}

1. Para un revisión crítica de los resultados de este estudio, véase Sánchez Avendaño (d).

2. "La referencia acertada depende de que el oyente identifique, con el fin de comprender el mensaje lingüístico en curso, el referente pretendido por el hablante en virtud de la expresión referencial empleada" (Brown y Yule 1993:253).

3. A riesgo de simplificar en demasía, se puede decir que la memoria de trabajo, también conocida como memoria de corto plazo, es un mecanismo especializado en almacenar cantidades de información pequeñas durante poco tiempo. En contraste, la memoria de largo plazo guarda recuerdos en forma más duradera una vez que estos se han asociado de modo significativo con las experiencias y conocimientos previos en la memoria. La memoria de trabajo - de ahí su nombre- nos permite retener porciones de información durante el tiempo necesario para poder llevar a cabo tareas cognitivas complejas, como decodificar un texto; una vez que dichas tareas se han completado, los elementos guardados en la memoria de trabajo se pierden (Schacter 1999).

4. A modo de ejemplo, véase la lista de sinónimos de la palabra 'inteligente' proporcionada por el Diccionario Larousse (1986): esclarecido, lúcido, clarividente, sagaz, perspicaz.

5. Obviamente, lo común es que un problema de construcción textual venga emparejado con otros. En este ejemplo, se nota una clara deficiencia en el desarrollo del tema: este apenas se plantea y luego se da vueltas sobre el mismo asunto. Por lo demás, el texto está lleno de digresiones del autor y lugares comunes; presenta una segmentación y puntuación altamente descuidadas. En adelante, debe entenderse que hacemos abstracción del fenómeno que nos concierna particularmente, aunque se presenten muchos otros que ameriten un comentario aparte.

6. El déficit en el manejo de la elisión, que lleva incluso a la redacción de construcciones agramaticales, se puede apreciar en los muchos ejemplos que consignan Rodino y Ross (1985 :91-8).

7. Recuérdese aquí la distinción entre palabras de contenido y palabras funcionales o gramaticales. Las primeras son rubros léxicos que efectivamente remiten a un referente extratextual; es decir, que tienen un "significado" que se puede aislar del contexto, como ocurre con palabras como 'casa', 'correr' o 'lejos'. Las palabras funcionales, por su parte, se "llenan" semánticamente en el contexto comunicativo o con la referencia de las palabras de contenido: el determinante 'el' en español, por ejemplo, carece de un significado al estilo de 'casa'.

8. Los manuales para la enseñanza de la redacción, especialmente los que se ciñen a un método gramaticalista y patológico (véase Sánchez Avendaño a), se refieren a las faltas de concordancia, por lo general, en la sección de "vicios"; específicamente, en la categoría de los solecismos: "Se define solecismo como aquel vicio del lenguaje que consiste en cometer errores o faltas o alteraciones a las reglas dadas acerca del oficio y uso de las distintas partes de la oración. Bien puede decirse que el solecismo es un error que 
comete el 'escritor' y el hablante en el aspecto sintáctico" (Bolaños 2001: 155). Precisamente, por este afán purista, las prácticas propuestas rara vez corresponden a las necesidades de los aprendices en cuanto a aprender a "pulir" la construcción de los textos; antes bien, se dedican a la corrección de supuestos errores, como en "Se planteaban una serie de discusiones sobre temas relacionados con el aborto y las drogas, asunto trascendental y de suma importancia en la actualidad por el gran problema que acarrea" (220).

9. Para un análisis crítico del papel del estudio de la gramática en la educación secundaria, véase Sánchez Avendaño (2005): "Los objetivos de la instrucción gramatical: Reflexiones sobre la enseñanza de la lengua materna".

10. El estudio de DeMello (1997), basado en corpora de habla culta de doce grandes ciudades del mundo hispano, halló este fenómeno en todos los países estudiados, incluyendo Costa Rica. Este mismo trabajo recoge una buena cantidad de referencias a estudios de muchos sitios que consignan la amplia extensión del fenómeno; también recopila varias explicaciones que se han formulado al respecto.

11. En español, lo normal es que se reduplique el objeto indirecto de tercera persona por medio del pronombre 'le' ("Le compré un regalo a mi mamâ"), lo cual no suele ocurrir con el directo (* "Lo compré un regalo"). No obstante, para la reduplicación del objeto directo cuando el referente es humano y definido ("La conozco a María"), fenómeno descrito para el español argentino y de otras regiones del Cono Sur, véase Lipski (1994).

12. Como me lo hizo notar la Dra. Carla Jara Murillo, aquí el pronombre 'lo' se refiere, con toda probabilidad, a la forma 'esto'. En todo caso, es fácil apreciar lo dificultosa que resulta la interpretación del referente de tal elemento.

13. A todas luces, se trata de una construcción con agente indeterminado, conocida tradicionalmente en gramática como una oración impersonal eventual. Su propósito comunicativo consiste en aludir a un agente de identidad desconocida o poco precisa; en este caso, ¿quién debería poner penas más severas? ¿el Poder Judicial? ¿la Asamblea Legislativa? En el segundo ejemplo, ¿quiénes manipulan a las adolescentes? En todo caso, cuando en un texto de esta naturaleza se requiere ser vago en cuanto al referente (el sujeto, en este caso), la norma convencional de estilo en español exige recurrir a construcciones pasivas e impersonales con 'se' (Montolío y Santiago 2000: 168-71); las impersonales eventuales poseen un tinte demasiado coloquial.

14. Carla Jara (comentario personal) agrega que no solo interfiere, sino que radica en la interpretación. Para el hablante/escribiente no hay incoherencia. Los estudiantes cuyas redacciones venimos comentando no se dan cuenta de lo incoherentes que resultan sus textos, de ahí que ni siquiera se planteen el problema.

15. Así como existen elementos que sustituyen a los nombres o sustantivos (los pronombres), también encontramos en las lenguas proverbos ('hacer'), prooraciones ('sî') y muchos otros tipos de proformas; es decir, rubros léxicos con sentido impreciso que se llenan semánticamente con la referencia de otras palabras introducidas en el mismo discurso o por medio del aporte del contexto en que se verifica la comunicación.

16. Para mayor facilidad, indicamos el número de párrafo entre paréntesis. 


\section{Bibliografía}

Bolaños, Bolívar. 2001. Comunicación escrita. San José: EUNED.

Brown, Gillian y George Yule. 1993. Análisis del discurso. Madrid: Visor Libros.

Calsamiglia Blancafort, Helena y Amparo Tusón Valls. 2002. Las cosas del decir. Manual de análisis del discurso. Barcelona: Ariel.

Centro de Lingüística Aplicada. 2005. Actas-II. IX Simposio Internacional de Comunicación Social. Santiago de Cuba: Centro de Lingüística Aplicada.

De Beaugrande, Robert-Alain y Wolfgang Ulrich Dressler. 1997. Introducción a la lingüística del texto. Barcelona: Ariel.

De Kock, Josse y George DeMello. 1997. Lengua escrita y habla culta en América y España. Salamanca: Ediciones Universidad de Salamanca.

DeMello, George. 1997. “Le por les”. En: De Kock y DeMello (1997).

Diccionario Larousse. Sinónimos/Antónimos. 1986. México: Ediciones Larousse.

Figueras, Carolina y Marisa Santiago. 2000. "Planificación". En: Montolío (coord.).

González Araña, Corina y Carmen Herrero Aísa. 1997. Manual de gramática española. Gramática de la palabra, de la oración y del texto. Madrid: Editorial Castalia.

González Nieto, Luis. 2001. Teoría lingüística y enseñanza de la lengua (Lingüística para profesores). Madrid: Cátedra.

Jiménez Montero, Claudio. 1987. Un aporte al mejoramiento de la expresión escrita. Tesis de Licenciatura en Filología Española, Universidad de Costa Rica.

Lipski, John. 1994. El español de América. Madrid: Cátedra.

Lozano, Jorge, Cristina Peña-Marín y Gonzalo Abril. 1999. Análisis del discurso. Hacia una semiótica de la interacción textual. Madrid: Cátedra.

Montolío, Estrella (coord.). 2000. Manual práctico de escritura académica. Volúmenes 2 y 3. Barcelona: Ariel.

Montolío, Estrella y Marisa Santiago. 2000. "Objetividad e implicación en el texto académico". En: Montolío (2000), V.3. 
Núñez, Rafael y Enrique del Teso. 1996. Semántica y pragmática del texto común. Producción y comentario de textos. Madrid: Cátedra.

Pacheco Salazar, Viria y María Álvarez Flores. 1997. Comunicación escrita y oral. San José: GQ Impresos.

Rodino, Ana María y Ronald Ross. 1985/2001. Problemas de Expresión Escrita del Estudiante Universitario Costarricense. Un estudio de lingüística aplicada. San José: EUNED.

Rojas Porras, Marta y Róger Umaña Chacón. 1986. Actualización escrita de la variable estándar de la lengua y de los códigos de habla: aportación para una descripción crítica. Tesis de Licenciatura en Filología Española, Universidad de Costa Rica.

Rojas Porras, Marta. 1987. "Análisis del nivel discursivo: Registros escritos de undécimo año". Revista Educación. 11 (2): 15-22.

Sánchez Avendaño, Carlos. 2005. "Los objetivos de la instrucción gramatical: Reflexiones sobre la enseñanza de la lengua materna”. En: Centro de Lingüística Aplicada, Actas-II.

Sánchez Avendaño, Carlos. (a). "Historiografía de la enseñanza de la redacción en Costa Rica: los libros de texto". Revista de Filología y Lingüística (en prensa).

Sánchez Avendaño, Carlos. (b). "La puntuación y las unidades textuales: Una perspectiva discursiva para el estudio de los problemas de su uso y para su enseñanza". Revista Educación (en prensa).

Sánchez Avendaño, Carlos. (c). "Los conectores discursivos: Su empleo en redacciones de estudiantes universitarios costarricenses". Revista de Filología y Lingüística (por publicar).

Sánchez Avendaño, Carlos. (d). "Historia de un desencuentro: Investigación y enseñanza de la redacción en Costa Rica" (por publicar).

Schacter, Daniel L. 1999. En busca de la memoria. El cerebro, la mente y el pasado. Barcelona: Ediciones B.

Varela Barboza, Marubeni y Wálter Sandino Angulo. 1993. Redacción y ortografía. Una opción para todos. Heredia: Ediciones Marwal. 